\title{
Performance of a statespace multispecies model: What are the consequences of ignoring predation and process errors in stock assessments?
}

Trijoulet, Vanessa; Fay, Gavin; Miller, Timothy J.

Published in:

Journal of Applied Ecology

Link to article, DOI:

10.1111/1365-2664.13515

Publication date:

2020

Document Version

Peer reviewed version

Link back to DTU Orbit

Citation (APA):

Trijoulet, V., Fay, G., \& Miller, T. J. (2020). Performance of a statespace multispecies model: What are the consequences of ignoring predation and process errors in stock assessments? Journal of Applied Ecology, 57(1), 121-135. https://doi.org/10.1111/1365-2664.13515

\section{General rights}

Copyright and moral rights for the publications made accessible in the public portal are retained by the authors and/or other copyright owners and it is a condition of accessing publications that users recognise and abide by the legal requirements associated with these rights.

- Users may download and print one copy of any publication from the public portal for the purpose of private study or research.

- You may not further distribute the material or use it for any profit-making activity or commercial gain

- You may freely distribute the URL identifying the publication in the public portal 


\section{Journal of Applied Ecology}

DR VANESSA TRIJOULET (Orcid ID : 0000-0002-3831-1416)

Article type : Research Article

Handling Editor: Melinda Coleman

Performance of a state-space multispecies model: what are the consequences of ignoring predation and process errors in stock assessments?

Vanessa Trijoulet ${ }^{*}$, Gavin Fay ${ }^{2}$, Timothy J. Miller ${ }^{1}$

1 Northeast Fisheries Science Center, National Marine Fisheries Service, National Oceanic and Atmospheric Administration, 166 Water St., Woods Hole, MA 02543, USA

${ }^{2}$ Department of Fisheries Oceanography, School for Marine Science and Technology, University of Massachusetts Dartmouth, New Bedford, MA

* Current address: Section for Marine Living Resources, National Institute of Aquatic Resources, Technical University of Denmark, Kemitorvet, 2800 Kgs. Lyngby, Denmark

Correspondence: Vanessa Trijoulet, vtri@aqua.dtu.dk, Fax: + 4535883333

This article has been accepted for publication and undergone full peer review but has not been through the copyediting, typesetting, pagination and proofreading process, which may lead to differences between this version and the Version of Record. Please cite this article as doi: 10.1111/1365-2664.13515

This article is protected by copyright. All rights reserved 


\section{Abstract}

1. Having a realistic representation of ecosystems in fisheries models is important in the context of ecosystem-based fisheries management (EBFM). While different modeling approaches support EBFM, accounting for trophic interactions and uncertainty in stock dynamics is important for management advice. Multispecies models exist, but are rarely used for assessments. Most stock assessments are single species models and predation is subsumed into natural mortality, which is often an assumed known value. The use of state-space assessment models, which account for stochasticity in unobserved processes (process errors), is increasing. However, many stocks are managed assuming deterministic processes. Little is known of how ignoring predation and process errors in stock assessment can impact the perception of the stocks and therefore fisheries management.

2. We developed an age-structured multispecies operating model that simulated data with errors in observations, recruitment and fish abundance. Four estimation models (EMs) that differed according to whether or not they accounted for predation or process errors were fitted to the simulated data. Relative differences between true and predicted outputs were estimated as a measure of bias. Equilibrium unfished biomass was estimated for each model as a proxy reference point.

3. Ignoring predation had the largest impact on stock perception and resulted in large bias in parameters, derived outputs and absolute or relative reference points. Estimating unobserved processes was not sufficient in limiting the bias when natural mortality was misspecified.

4. Ignoring process errors had limited bias but the bias increased when no contrasts exist in fishing mortality over time.

5. Looking solely at likelihood values to choose among models is misleading and predictive ability could be used to prevent selecting models that overfit the data.

6. Synthesis and applications. Ignoring trophic interactions that occur in marine ecosystems induces bias in stock assessment outputs and results in low model predictive ability with 
subsequently biased reference points. While it may be difficult to estimate natural mortality when no data exist to inform it, stock managers should remember that, if predation is large, assuming a constant mortality over time and/or age could have large consequences on stock perception and reference point estimates and affect resulting management advice.

Keywords: ecosystem-based fisheries management, multispecies stock assessment, predation, natural mortality, reference points, state-space model, Template Model Builder, trophic interactions.

\section{Introduction}

Most of the world's fisheries that rely on stock assessments as the basis of scientific advice for management are assessed using single species models that only account for the dynamics of a specific fish stock and the fishing pressure on this stock (Skern-Mauritzen et al. 2015), with pressures such as environmental variability, predation and residual natural mortality often assumed known and constant over time. However, fish stocks are part of large food webs and trophic pressures may vary with the predators' dynamics, which is inconsistent with the assumption of constant natural mortality. Therefore there has been a shift towards developing ecosystem management, which can range in complexity to fisheries specific management where biotic and abiotic factors (e.g. climate change, predators) are incorporated individually in single species assessments, to management where other uses of the marine ecosystem, such as renewable energy or tourism are also modeled (Dolan et al. 2016). Ecosystem-based fisheries management (EBFM) focuses on fishing activities, including biological, physical and economic considerations and therefore represents a holistic approach to fisheries management (Link 2010). EBFM is currently strongly supported by numerous international agencies (FAO 2003, NOAA 2016).

Multispecies population models are becoming important tools for supporting EBFM approaches (Plagányi 2007). These models account for trophic interactions in the dynamics of the different species simultaneously and are therefore a more realistic representation of the structure of the 
ecosystem. Different levels of complexity exist in multispecies modeling. Whole ecosystem models, such as Atlantis (Fulton et al. 2004) or Ecopath with Ecosim (Christensen and Walters 2004), are generally simulation models and predation is only informed empirically using diet data or estimates from the literature, and usually deterministically assumed in models. These models are useful to understand functional aspects of the ecosystem or to test management scenarios (Fulton et al. 2014, Grüss et al. 2016, Weijerman et al. 2016). However, simulation models are less adequate for supporting tactical management advice, since parameters defining the dynamics of the populations should be estimated from data specific to the ecosystem, to evaluate weight of evidence for alternative hypotheses about the population dynamics and to characterize uncertainty in our understanding of the ecosystem. In this case, statistical multispecies stock assessment models are more relevant. These assessment models are usually of moderate complexity and only focus on the components of the ecosystem which are biologically or economically relevant for addressing management questions, and ignore prey feedbacks on the predator such as food limitation effects on predator's growth (Plagányi et al. 2014). Development of multispecies assessment models has increased with the importance of EBFM with models ranging from simple deterministic Multispecies Virtual Population Analysis (MSVPA) models (Helgason and Gislason 1979, Tsou and Collie 2001) to more complex multispecies statistical catch-at-age models (Lewy and Vinther 2004, Jurado-Molina et al. 2005, Kinzey and Punt 2009, Curti et al. 2013). Among these models, multispecies age-structured assessments are of particular interest since age information is often available and many stock assessments are structured by age. These multispecies models follow the concept of MSVPA that emerged in the late 1970s with Andersen and Ursin (1977). However, multispecies agestructured models are still rarely used to assess fish stocks. For instance, in the North Atlantic, the stochastic multispecies model (SMS) developed by Lewy and Vinther (2004) is currently used for management advice, by providing values of natural mortality to North Sea and Baltic Sea single species stock assessment models (ICES 2018) but is not directly used as the assessment model for these species.

In addition to multispecies models, there is an incentive to develop state-space stock assessment models that account for uncertainty in sampling that generates observations 
(observations errors) and also in unobserved biological processes responsible for stochastic changes in the population over time (process errors). These state-space models treat the process errors as random effects which are integrated out to estimate fixed effects parameters from the marginal likelihood of the observations (Aeberhard et al. 2018). By estimating both types of errors, these state-space models become a more realistic illustration of the uncertainty that exists in our understanding of the fisheries systems. Despite the fact that state-space single species assessments are becoming popular and easy to implement (Nielsen and Berg 2014, Berg and Nielsen 2016, Miller et al. 2016), many stock assessments are still based on models that ignore process errors or treat them as fixed variations. State-space multispecies fisheries assessments are even less common.

Here, we investigate how ignoring process errors and trophic interactions affects stock assessment model performance and fisheries management. A simulation study was conducted using the multispecies stock assessment model of Trijoulet et al. (2019) extended to account for process errors in recruitment and fish abundance at age. The model was used to simulate data sets that were then fitted to four estimation models that differed in whether they accounted for predation and process errors. Model performance was determined by calculating relative differences between true and estimated values. Fits to the data and predictive ability of the models were analyzed. The consequences of model assumptions on the estimation of absolute and relative proxy reference points were also evaluated.

\section{Materials and Methods}

\subsection{State-space multispecies operating model}

The study used the multispecies age-structured model presented in Trijoulet et al. (2019) and developed in Template Model Builder (TMB) (Kristensen et al. 2016). It was applied to two fish species, modeled to be characteristic of Georges Bank Atlantic cod (Gadus morhua) (Northeast Fisheries Science Center 2015) and Northwest Atlantic herring (Clupea harengus) (Deroba 2015). Cod is assumed to prey on both herring and small cod. The model equations are summarized in Table 1 and the model settings in the Supporting information (part 1). Trophic

This article is protected by copyright. All rights reserved 
interactions were assumed to be large between the predator and the prey as illustrated in Supporting information (part 2).

The model of Trijoulet et al. (2019) was extended to include process errors on recruitment at age 1 and annual fish abundance at age. Annual log-recruitment for species $i$ was assumed to be distributed normally with mean $\bar{R}_{i}$ and variance $\sigma_{R_{i}}^{2}$ (Table 1, equation T1.20). The process error in $\log$ abundance was a random walk assumed to follow a Normal distribution with variance $\sigma_{N_{i}}^{2}$ (Table 1, equation T1.21).

The state-space model was used as an operating model to simulate 1000 data sets of observations with errors on the annual total fishing catches by species, annual aggregated (over ages) survey abundance indices, age composition of catch and survey, and the diet of predators. Log total fishing catches and indices for each species were assumed normally distributed and age compositions for both were assumed multinomial distributed (Table 1, equations T1.15 to T1.18). The diet data was composed of proportions of prey by weight in the stomach of the predator and were generated per predator age and year (EM2 in Trijoulet et al. (2019)) and these were assumed to follow a Dirichlet distribution (Table 1, equation T1.19). Process errors in recruitment and abundance were simulated per equations T1.20 and T1.21.

\subsection{Estimation models}

The study considered four estimation models (EMs) to be used for tactical management:

- EM1: state-space multispecies model estimating fishing, predation and residual natural mortality. It has the same configuration as the operating model and estimates process errors on recruitment and fish abundance.

- EM2: multispecies statistical catch-at-age model estimating fishing, predation and residual natural mortality. Process errors were not accounted for in this model so changes in fish abundance were assumed deterministic and annual values of recruitment were estimated with no distributional constraint. This model allows investigation of how ignoring process error in stock assessment may impact model performance.

This article is protected by copyright. All rights reserved 
For EM1 and EM2, diet data was fitted using equation T1.19 where diet observations were annual proportions of prey (in weight) present in the diet of cod and given for each predator age.

- EM3: state-space model assuming total natural mortality constant across ages and time. Trophic interactions were not explicitly estimated, so the estimate of total natural mortality from this model corresponds to $M+P$. This model investigates the consequences of ignoring predation and assuming that natural mortality is constant over age and time, an assumption commonly made in stock assessment practice (Northeast Fisheries Science Center 2015), with the exception that $M$ is estimated here while it is often fixed at a known value in stock assessments.

- EM4: state-space model estimating age-varying natural mortality. The natural mortality was assumed to follow an allometric relationship with weight at age (Ursin 1967, Peterson and Wroblewski 1984, Lorenzen 1996) and with parameters of this relationship being estimated ( $\alpha$ and $\beta$ in equation 1 ).

$M_{a, i}=\alpha_{i} w_{a, i}^{\beta_{i}}$ eqn 1

To aid the estimation of natural mortality, prior distributions parameterized using estimates in Lorenzen (1996) were used:

$\alpha_{i} \sim \mathcal{N}\left(3.69,0.5^{2}\right) \quad$ eqn 2

$\beta_{i} \sim \mathcal{N}\left(-0.305,0.028^{2}\right) \quad$ eqn 3

EM4 investigates how not explicitly accounting for predation could impact model performance when age-varying total natural mortality $(M+P)$ is still estimated. Assuming equation 1 forces natural mortality to decrease with fish age which most resembles the shape of $M+P$ in the simulated data sets (higher predation mortality on younger fish). An allometric $M$ is sometimes used in stock assessment but $\alpha$ and $\beta$ are usually fixed at the Lorenzen values rather than estimated (ICES 2017). For simplicity, in all models, the annual weight at age of both fish species was constant over time and given by the averaged weight over time from the recent stock 
assessments for each species (Deroba 2015, Northeast Fisheries Science Center 2015). This resulted in an estimated $M$ at age constant over time for EM4.

Given that predation mortality in the simulated data sets varies per age and over time, the EMs 3 and 4 are expected to show some bias due to misspecification of the total natural mortality but, whether the performance of these models assuming a constant natural mortality across time (EM4) and ages (EM3) are substantially degraded is consequential, since these are commonly made assumptions in practice.

Estimated parameters included fishing mortality parameters (fully selected annual fishing mortality $f_{t}$ and parameters governing selectivity at age $\gamma^{F}$ and $A 50^{F}$ ), survey abundance index parameters (survey catchability $q$ and selectivity at age parameters, $\gamma^{\text {surv }}$ and $A 50^{\text {surv }}$ ), the abundance at age in the first year $\left(N_{1, a, i}\right)$, the predation parameters (general vulnerability $\rho$ and Dirichlet distribution parameter $\kappa$ ), annual recruitment at age $1\left(N_{t, 1, i}\right)$ (EM2 only), and residual natural mortality per prey species $\left(M_{i}\right.$, EM1-EM3) or Lorenzen parameters ( $\alpha$ and $\beta$, EM4). With $M$ being held constant across ages and years in the OM, only one value of $M$ was estimated by prey species in EM1-EM3. Additional estimated parameters in EM1, EM3 and EM4 included mean recruitment $\left(\bar{R}_{i}\right)$, standard errors $\left(\sigma_{R_{i}}\right)$ for the recruitment process, the matrix of numbers at age $(\hat{N})$ and standard errors on fish abundance $\left(\sigma_{N_{i}}\right)$.

\subsection{Sensitivity analyses}

Two sensitivity analyses were carried out. First, the simulations were also run assuming a constant fully selected fishing mortality $(f)$ in the $\mathrm{OM}$, which resulted in a constant $F$ at age over time, to see how having no contrast in annual fishing mortality may impact the performance of the models. Second, we explored the effect of misspecification of the process error structure. In the OM the source of process error with the largest variance is recruitment. An additional EM (EM1b) was fitted to the 1000 simulated data sets where recruitment was assumed to follow a random walk with estimated variance instead of being random about an estimated mean (original EM1). This model testes if misspecification in process error affects bias of EM1.

This article is protected by copyright. All rights reserved 


\subsection{Convergence criteria and performance metrics}

Each EM was fitted to the 1000 simulated data sets. Convergence was diagnosed by a maximum gradient component less than 0.0001 and a positive definite hessian matrix.

Median relative differences (RD) were estimated across all converged iterations for estimated parameters and derived outputs $(\hat{\theta})$.

$R D=\frac{\hat{\theta}}{\theta}-1 \quad$ eqn 4

where $\theta$ is the true value of the parameter or derived output. The $95 \%$ confidence intervals of the median RD were estimated using the binomial distribution method of Thompson (1936).

Diet data was not used in EM3 and EM4, so the EMs were not comparable using selection criteria such as the Akaike information criterion. Quality of fit to the observed data was assessed by taking the difference between the negative log-likelihood (NLL) values in each simulation for EM1 and the NLLs for the misspecified models (EM2-EM4).

A model's ability to provide accurate projections of the stocks can be evaluated by studying the predictive ability of the models. The EMs were run omitting the observed aggregated indices and their corresponding age composition in the last 5 years of the time series. Predictions were compared to the missing observations using equation 4 for the four EMs. Models that show the least bias in predicted indices should provide most robust forecasts.

Only the converged outputs were kept for analysis, resulting between 293 and 931 iterations depending on the EM. It was chosen not to run more simulations even if the number of convergences was low so that all models used the same data sets. A sensitivity analysis running more simulations to obtain 1000 converged runs for the EMs that resulted in the smallest number of convergences gave median RD values similar to the original outputs (results not shown). The number of convergences only affected the size of the confidence interval around the median RD.

\subsection{Proxy reference point estimation}

This article is protected by copyright. All rights reserved 
Since the models did not estimate a stock recruitment relationship, the impact of considering trophic interactions and process errors on reference point estimates was investigated by estimating a proxy reference point, unfished biomass $\left(B_{0}\right)$. For each model and each iteration (OM and EMs), equilibrium unfished biomass was obtained by projecting both stocks forward for an additional 500 years with $F=0$ and with the same assumptions in the forecasts as in the models (e.g. for the multispecies state-space EM1, random walk on recruitment was assumed in the forecast given the mean and standard deviation estimates for each EM1 iteration). Input values such as mean weight at age were set as the average over the 42 years used in the simulated data sets. For EM2, forecast recruitment was the average over the 42 years and assumed constant. Unfished biomass was estimated by taking the average spawning stock biomass (SSB) over years 400-500. For the multispecies models, the prey abundances depend on the predator abundance so both stocks oscillate around an equilibrium rather than approaching a constant SSB value. Unfished biomass corresponds therefore to this equilibrium. To limit variability due to process errors in the forecasts, for the models with process errors (OM, EM1, EM3 and EM4), 100 runs were made for each iteration and $B_{0}$ was calculated as the average over these 100 iterations. To keep consistency in the forecasts for all models, we also ran the same simulations with no process error in the projections.

For each iteration, the relative differences were calculated between $B_{0}$ estimated in the forecasts with the OM with $B_{0}$ in the EM's forecasts to see how the EMs performed regarding the estimation of the absolute reference point. Bias on a relative scale was also calculated by taking the ratio between the last estimated SSB $\left(S S B_{y}=42\right)$ and $B_{0}$ in the forecasts for each model iteration. These ratios were compared to the same ratios obtained in the $\mathrm{OM}$ to assess possible bias in estimation of relative reference point.

To understand the trade-offs associated with fishing opportunities in a multispecies context, we also investigated how equilibrium SSB estimates varied compared to $B_{0}$ for different combinations of fishing mortality on both species for the $\mathrm{OM}$. We used $F$ multipliers between 0 and 2 with a step of 0.1 on both species (for a total of 441 combinations of $F$ on cod and herring) and projected the stocks forward for 500 more years. As for previous projections, process

This article is protected by copyright. All rights reserved 
errors on recruitment and abundance at age were assumed in the forecasts and 100 iterations were run per $F$ combination. We looked at how the ratios of equilibrium SSB for each $F$ combination (average years 400-500) against $B_{0}$ varied with changes in $F$ for both species.

\section{Results}

The convergence rate varied considerably among the EMs (Table 2). EM2 converged most frequently followed by EM1. The EMs not explicitly accounting for predation (EM3 and EM4) had low convergence rates.

EM1, which had the same configuration as the OM, performed best in estimating the parameters with a maximum bias around $-0.4 \%$ for cod catchability ( $q$, Fig. 1$)$. The numbers at age in the first year were slightly underestimated with a maximum bias of $-6 \%$ (Fig. 2). Assuming deterministic recruitment and change in fish abundance (EM2) increased the bias compared to EM1, notably in survey catchability for both species but the bias was below $3 \%$ for all parameters. Numbers of fish in the first year were underestimated with bias between - $2 \%$ and 8\%. When predation was not explicitly estimated (EM3 and EM4), estimation bias increased for most parameters, from 2 to 52\% for EM3 and 2 to 220\% for EM4 (Fig. 1). The largest bias observed was in estimates of cod mean recruitment and herring catchability for EM3 (-38\% and $-52 \%$ respectively) and in herring catchability and mean recruitment for EM4 (-47\% and $220 \%$ respectively). EM3 overestimated fish numbers in the first year, notably for herring where the bias reached $336 \%$ (Fig. 2). Numbers at age in the first year were overestimated for cod (up to $46 \%$ ) and herring (up to 442\%) when $M$ was modelled as a function of fish weight (EM4).

Negative bias in maximum likelihood estimates of process error variances is expected. Here, EM1 underestimated the variance in annual abundance at age for cod and herring ( $-27 \%$ and $34 \%$ respectively, Fig. 3). Variance of annual recruitment was only slightly underestimated (2$3 \%$ for both species). However, the models ignoring predation overestimated the variance in process errors on the abundance at age for herring and recruitment variance for both species. Variance of the process error on the abundance at age for cod for both EM3 and EM4 was estimated to be close to zero.

This article is protected by copyright. All rights reserved 
Spawning stock biomass (SSB) and recruitment were well estimated for EM1 and the bias slightly increased below $-1-2 \%$ for SSB and -3\% for recruitment with EM2 (Fig. 4). Estimation bias increased substantially for EM3 and EM4 and was maximal for herring with a bias in SSB and recruitment of $23-100 \%$ for EM3 and $73-229 \%$ for EM4.

As expected, EM1 showed the smallest bias in estimated mortality rates, with these being well estimated for both species (Fig. 5). The largest bias was for cod residual natural mortality and was around 1.4\%. Ignoring process errors (EM2) induced a larger bias in estimated $M$ of around $-5 \%$ for cod and $-5.6 \%$ for herring. As a result, fishing and predation mortality were slightly overestimated for both species. Not explicitly accounting for predation (EM3 and EM4) had the largest impact on estimation bias, most notably for herring where $F$ was underestimated (median around -50\%) and $M$ overestimated (around 23\%) for both EM3 and EM4.

On average, EM2 presented larger NLLs than EM1 for all types of observed data demonstrating that EM1 fitted the data better than EM2 (Fig. 6). However, EM3 and EM4 fitted the aggregated catch and the age compositions for the catch and surveys better than EM1.

EM1 and EM2 were robust in predicting the observed values for survey indices in the last 5 years of the times series despite the absence of data on aggregated indices and their age composition, with a difference between observed and predicted indices below 2\% (Fig. 7). However, when predation was ignored, bias in predicted indices increased in the last years of the time series as did the uncertainty around the median estimates. As a result, EM3 and EM4 present a clear increase in bias in predicted SSB at the end of the time series while bias was still low for this period in EM1 and EM2 (Fig. 8).

When $f$ was held constant over time in the OM, only EM1 showed small bias in estimated parameters and derived outputs (Supporting information, part 3.1). Bias in EM1 and EM2 increased compared to the original results (Figs. S4-S8), with parameters and derived outputs that were slightly biased in the original simulations having larger bias. The bias in estimates of $M$ went from $5-6 \%$ to $11-17 \%$ for EM2 (Fig. S8) and bias in SSB and recruitment from 1-2\% to $>6 \%$ and from $3 \%$ to $>10 \%$, respectively (Fig. S7). For EM4, no contrast in $F$ at age over time in

This article is protected by copyright. All rights reserved 
the OM had the opposite effect (smaller bias than original simulations) but the bias was still larger than obtained for EM1 and EM2, with $0-60 \%$ bias in parameter estimates (Figs. S4-S5) and $20-60 \%$ bias in SSB and recruitment (Fig. S7). For EM3, no contrast in $F$ over time led to an inability to estimate true values for herring recruitment (Fig. S7) and mortality (Fig. S8). $F$ was overestimated and $M$ was reduced to 0 .

Misspecifying recruitment process error in EM1b had a small effect on estimation bias (Supporting information, part 3.2). Biases in herring SSB, recruitment (Fig. S11) and mortality rates (Fig. S12) increased slightly compared to EM1 but overall were similar. Bias in all parameters and outputs were smaller than for EM2.

Bias in absolute $\left(B_{0}\right)$ and relative $\left(\frac{S S B_{y=42}}{B_{0}}\right)$ reference points was largest for the single species models (EM3 and EM4, Fig. 9). Bias was also large for EM2 ( $\simeq 20 \%)$ compared to EM1 because of the absence of process errors in the forecasts compared to the $\mathrm{OM}$, inducing a change in the assumption about recruitment. The bias was largely reduced for EM2 when no process error was assumed in the forecasts for all models (Supporting information, part 4, Fig. S13).

Increasing $F$ on cod or herring reduced the equilibrium SSB for the respective species (Fig. 10). However, increased $F$ on herring did not affect equilibrium unfished cod SSB and increased $F$ on cod increased equilibrium unfished herring SSB (ratio $>1$ ) faster than the decrease in herring SSB when $F$ increased on herring.

\section{Discussion}

Modeling predator-prey interactions and predator impacts on prey abundance has been proven important in systems outside of marine fisheries including terrestrial environments (Hanski et al. 2001, Owen-Smith and Mills 2008), aquatic systems (Tsehaye et al. 2014) and across ecosystems (Knight et al. 2005). Here, we show that ignoring trophic interactions in fisheries stock assessment models (EM3 and EM4) when these are strong can bias estimates of dynamics and population parameters and can result in low model predictive ability. These biases could affect stock management as they result in biased reference point estimates on both absolute and relative scales. Assuming a known natural mortality fixed as constant over time and sometimes 
ages is a common approach used in stock assessment (Lee et al. 2011, Johnson et al. 2015, Miller and Hyun 2018). It is therefore important to know that, despite a fit to observed data that could be perceived as reasonable (Fig. 6), misspecifications of natural mortality can affect the perception of fish stock status irrespective of harvest history (EM3 and EM4 had large bias for both constant and varying $F$ ), and the consequences of these changes in perception on catch advice can be great.

By estimating process errors, state-space models could potentially compensate for ignoring unobserved variability due to predation. However, our results suggest that models that did not explicitly account for trophic interactions (EM3 and EM4) were unable to get consistent process error estimates and to differentiate between process errors on abundance and recruitment. Using state-space models to model unobserved mortality such as predation and residual natural mortality was not sufficient to limit bias. These misspecified models also resulted in the lowest convergence rates illustrating the difficulty in estimating parameters when natural mortality is misspecified. The role of observed data and assumptions on natural mortality in the ability of models to distinguish among sources of variability in population dynamics processes should be an area for future work.

Most stock assessment models assume deterministic processes (Dichmont et al. 2016). Here, we showed that ignoring process errors in a multispecies context (EM2) had a small impact on model performance, while providing a high convergence rate (Table 2). Ignoring process errors induced relatively low bias in parameter estimation when annual contrasts in fishing mortality were assumed. Low bias was also observed in reference point estimation when the forecast assumptions were the same as in the OM. However, these biases may increase if no contrast exists between the different mortality rates, likely due to difficulty in partitioning total mortality into the different mortality rates when there is little contrast in mortality rates and process errors are ignored. Bias in proxy reference point estimates also increased when compared to the OM forecasts that accounted for unobserved variability in both stocks. This was mainly due to the difference in recruitment assumption, which matters when forecasting fish stocks. Estimating process errors in fisheries models should result in more robust parameters and 
derived outputs (Aeberhard et al. 2018) even if process errors are misspecified or their variances underestimated (EM1, EM1b) because this more closely reflects the emergent complexity of the biological processes in fisheries ecosystems.

Statistics derived from likelihood values are commonly used for model selection, e.g. Akaike information criterion (AIC) and Bayesian information criterion (BIC) (Schwarz 1978, Akaike 1987). Here, we showed that looking solely at likelihood values to choose the best model can be misleading since misspecified models (EM3 and EM4) may overfit the observations and perform poorly at predicting unobserved data. Models that overfit the data were imprecise at forecasting, with large consequences for fisheries management if they were chosen as the basis for advice, since reference point estimates could be incorrect on both the absolute and relative scale. In practice, an analyst does not know which of a set of models best represents the system being observed and the goal of model selection is to determine which of the set does this. EM3 and EM4 fit the observed data best for three of the four data types despite misspecification in $M$. In this particular case, it was important to check the predictive ability of the models, which was very poor, to reject both models for providing management advice.

Multispecies fisheries models have been recognized to improve estimates of natural mortality and recruitment and provide a framework for ecosystem-based management (Hollowed et al. 2000, Plagányi 2007). Here, multispecies models (EM1 and EM2) provided robust outputs and outperformed single species models (EM3 and EM4). Predictive ability of the models and estimation of reference points were also improved in the multispecies cases. However, defining optimal yield for fisheries is not straightforward in multispecies models (Fogarty 2013, Moffitt et al. 2016). It is not generally possible to maximize the yield of several species simultaneously, and maximizing an aggregate yield can lead to complete collapse of one or more species (Gaichas et al. 2012). Even our relatively simple forecasts of a two-species system without stock-recruit relationships illustrates this difficulty (Fig. 10). Methods for determining, communicating and visualizing the trade-offs associated with multispecies reference points are needed to improve our understanding of the consequences of considering trophic interactions on the management of natural resources.

This article is protected by copyright. All rights reserved 
The state-space multispecies model developed in this study and extended from the statistical catch-at-age model of Trijoulet et al. (2019) was proven a consistent tool to assess fish stocks in a stochastic multispecies context. Indeed, the estimation model that shared the OM configuration (EM1) showed little bias in all parameters and derived outputs and was robust in estimating fishing, predation, and residual natural mortality even when process error on recruitment was misspecified (EM1b). The maximum bias was on the variance of the process errors on fish abundance $(\simeq-30 \%)$, larger than bias in recruitment process error standard deviation $(\simeq-3 \%)$. Underestimating process error variances is common in simulation testing and larger underestimation of variance in process errors on fish abundance compared to recruitment was also observed in state-space single species models (Miller and Hyun 2018). Auger-Méthé et al. (2016) demonstrated that estimation bias can occur when observation errors are larger than process errors. Here, this was the case for process errors on fish abundance but not for process errors on recruitment, and this could explain the observed difference in bias.

For the models not explicitly accounting for predation (EM3 and EM4), parameter bias was generally larger for herring than for cod. This was because predation is highest on herring compared to cod and misspecifiying total natural mortality $(M+P)$ on this stock will have larger impact than misspecifying it for cod. Estimating time or age varying mortality might be expected to result in better performance than a constant value across ages and over time. In our study, one would expect EM4 to be a better model than EM3, since EM4 accounts at least for agevarying total natural mortality. However, EM4 showed the largest bias. Similarly, constant natural mortality gave better results than age-varying mortality in state-space single species assessment (Miller and Hyun 2018). Deroba and Schueller (2013) also concluded that misspecification of temporal variations in $M$ results in more bias than variation with age for single species statistical catch-at-age models, when $M$ is assumed known. This could also be the case in our example, but it was not possible to estimate time-varying $M$ with our EMs (only 5 convergences over 1000 iterations). Temporal variation in $M$ was estimated in Johnson et al. (2015), but $M$ in their OM was constant across ages. While it may be possible to estimate a

This article is protected by copyright. All rights reserved 
constant $M$ in assessment models, if $M$ varies over time and ages the task seems difficult to achieve without data to inform it.

Ignoring trophic interactions may have large consequences in stock assessments but modeling predation is often compromised by paucity of diet data. While stomach content data have been collected annually in the Northeast US since 1973 (Smith and Link 2010), only 5 years of diet data are available in the North Sea (ICES 1997). The annual age-based diet data simulated here may then be more exhaustive than data currently available for many ecosystems. Our study only considered two species and we simulated strong predation of one species on the other. This is a large simplification of the complex structure of real fisheries systems where there may be numerous weak interactions of many species. The consequences of ignoring predation may therefore be less pronounced in a system with a larger number of prey and predators. Trijoulet et al. (2019) demonstrated predation can be estimated even if interactions are weak or diet data is sparse, highlighting the importance of estimating predation when diet data is available. Modeling predation explicitly could be a way forward for achieving time and age-varying natural mortality when diet data is available. In the case of an absence of predator diet data, if natural mortality is misspecified, managers should be aware of the large bias that can result on stock assessment outputs and on reference points that could be used for tactical management advice.

\section{Authors' contributions}

VT and TJM conceived the ideas and designed methodology; VT collected the data; VT, GF and TJM analyzed the data; VT led the writing of the manuscript. All authors contributed critically to the drafts and gave final approval for publication.

\section{Acknowledgements}

This project was funded by NOAA Fisheries' FY16 Stock Assessment Analytical Methods internal request for proposal. We thank Jon J. Deroba, Daniel Howell, an anonymous reviewer and the associate editor for their helpful comments on the manuscript.

\section{Data accessibility}

This article is protected by copyright. All rights reserved 
Models and data are available via Zenodo https://doi.org/10.5281/zenodo.3407512 (Trijoulet et al. 2019) and via VT's GitHub repository "Multisp_model_JAE" following the link: https://github.com/vtrijoulet/Multisp_model_JAE.

\section{References}

Aeberhard, W. H., J. Mills Flemming, and A. Nielsen. 2018. Review of State-Space Models for Fisheries Science. Annual Review of Statistics and Its Application 5:215-235 doi:10.1146/annurev-statistics-031017-100427.

Akaike, H. 1987. Factor analysis and AIC. Pages 371-386 Selected papers of hirotugu akaike. Springer.

Andersen, K. P., and E. Ursin. 1977. A multispecies extension to the Beverton and Holt theory of fishing, with accounts of phosphorus circulation and primary production. Pages 319- 435 Meddelelser Fra Danmarks Fiskeri- OG Havundersogelser. The Danish Institute for Fishery and Marine Research, Copenhagen.

Auger-Méthé, M., C. Field, C. M. Albertsen, A. E. Derocher, M. A. Lewis, I. D. Jonsen, and J. Mills Flemming. 2016. State-space models' dirty little secrets: even simple linear Gaussian models can have estimation problems. Scientific Reports 6:26677 doi:10.1038/srep26677.

Berg, C. W., and A. Nielsen. 2016. Accounting for correlated observations in an age-based statespace stock assessment model. ICES Journal of Marine Science 73:1788-1797 doi:10.1093/icesjms/fsw046.

Christensen, V., and C. J. Walters. 2004. Ecopath with Ecosim: methods, capabilities and limitations. Ecological Modelling 172:109-139 doi:10.1016/j.ecolmodel.2003.09.003.

Curti, K. L., J. S. Collie, C. M. Legault, and J. S. Link. 2013. Evaluating the performance of a multispecies statistical catch-at-age model. Canadian Journal of Fisheries and Aquatic Sciences 70:470-484 doi:10.1139/cjfas-2012-0229.

Deroba, J. J. 2015. Atlantic herring operational assessment report 2015. Page 30 in US Department of Commerce, editor., Northeast Fisheries Science Center Reference Documents 15-16.

This article is protected by copyright. All rights reserved 
Deroba, J. J., and A. M. Schueller. 2013. Performance of stock assessments with misspecified ageand time-varying natural mortality. Fisheries Research 146:27-40 doi:10.1016/j.fishres.2013.03.015.

Dichmont, C. M., R. A. Deng, A. E. Punt, J. Brodziak, Y.-J. Chang, J. M. Cope, J. N. Ianelli, C. M. Legault, R. D. Methot, C. E. Porch, M. H. Prager, and K. W. Shertzer. 2016. A review of stock assessment packages in the United States. Fisheries Research 183:447-460 doi:https://doi.org/10.1016/j.fishres.2016.07.001.

Dolan, T. E., W. S. Patrick, and J. S. Link. 2016. Delineating the continuum of marine ecosystembased management: a US fisheries reference point perspective. ICES Journal of Marine Science 73:1042-1050 doi:10.1093/icesjms/fsv242.

FAO. 2003. The ecosystem approach to fisheries. Page 112 in Fisheries Department, editor. FAO Technical Guidelines for Responsible Fisheries, Rome.

Fogarty, M. J. 2013. The art of ecosystem-based fishery management. Canadian Journal of Fisheries and Aquatic Sciences 71:479-490 doi:10.1139/cjfas-2013-0203.

Fulton, E. A., A. D. M. Smith, and C. R. Johnson. 2004. Effects of spatial resolution on the performance and interpretation of marine ecosystem models. Ecological Modelling 176:27-42 doi:10.1016/j.ecolmodel.2003.10.026.

Fulton, E. A., A. D. M. Smith, D. C. Smith, and P. Johnson. 2014. An Integrated Approach Is Needed for Ecosystem Based Fisheries Management: Insights from Ecosystem-Level $\begin{array}{lllll}\text { Management Strategy } & \text { Evaluation. PloS one 84242 }\end{array}$ doi:10.1371/journal.pone.0084242.

Gaichas, S., R. Gamble, M. Fogarty, H. Benoît, T. Essington, C. Fu, M. Koen-Alonso, and J. Link. 2012. Assembly rules for aggregate-species production models: simulations in support of management strategy evaluation. Marine Ecology Progress Series 459:275-292.

Grüss, A., W. J. Harford, M. J. Schirripa, L. Velez, S. R. Sagarese, Y.-J. Shin, and P. Verley. 2016. Management strategy evaluation using the individual-based, multispecies modeling approach OSMOSE. Ecological Modelling 340:86-105 doi:10.1016/j.ecolmodel.2016.09.011. 
Hanski, I., H. Henttonen, E. Korpimäki, L. Oksanen, and P. Turchin. 2001. Small-rodent dynamics and predation. Ecology 82:1505-1520 doi:10.1890/00129658(2001)082[1505:SRDAP]2.0.C0;2.

Helgason, T., and H. Gislason. 1979. VPA-analysis with species interaction due to predation. International Council for the Exploration of the Sea, Demersal Fish Committee.

Hollowed, A. B., P. Livingston, N. Bax, R. Beamish, J. Collie, M. Fogarty, J. Pope, and J. C. Rice. 2000. Are multispecies models an improvement on single-species models for measuring fishing impacts on marine ecosystems? ICES Journal of Marine Science 57:707-719 doi:10.1006/jmsc.2000.0734.

ICES. 1997. Database report of the stomach sampling project 1991.

ICES. 2017. Report of the Working Group on Celtic Seas Ecoregion (WGCSE). 9-18 May 2017, Copenhagen, Denmark. ICES CM 2017/ACOM:13.

ICES. 2018. Interim Report of the Working Group on Multispecies Assessment Methods (WGSAM). 16-20 October 2017, San Sebastian, Spain. ICES CM 2017/SSGEPI:20.

Johnson, K. F., C. C. Monnahan, C. R. McGilliard, K. A. Vert-pre, S. C. Anderson, C. J. Cunningham, F. Hurtado-Ferro, R. R. Licandeo, M. L. Muradian, K. Ono, C. S. Szuwalski, J. L. Valero, A. R. Whitten, and A. E. Punt. 2015. Time-varying natural mortality in fisheries stock assessment models: identifying a default approach. ICES Journal of Marine Science 72:137-150 doi:10.1093/icesjms/fsu055.

Jurado-Molina, J., P. A. Livingston, and J. N. Ianelli. 2005. Incorporating predation interactions in a statistical catch-at-age model for a predator-prey system in the eastern Bering Sea. Canadian Journal of Fisheries and Aquatic Sciences 62:1865-1873 doi:10.1139/f05-110.

Kinzey, D., and A. E. Punt. 2009. Multispecies and single-species models of fish population dynamics: comparing parameter estimates. Natural Resource Modeling 22:67-104 doi:10.1111/j.1939-7445.2008.00030.x.

Knight, T. M., M. W. McCoy, J. M. Chase, K. A. McCoy, and R. D. Holt. 2005. Trophic cascades across ecosystems. Nature 437:880 doi:10.1038/nature03962.

This article is protected by copyright. All rights reserved 
Kristensen, K., A. Nielsen, C. W. Berg, H. Skaug, and B. M. Bell. 2016. TMB: Automatic Differentiation and Laplace Approximation. Journal of Statistical software 70:1-21 doi:10.18637/jss.v070.i05.

Lee, H. H., M. N. Maunder, K. R. Piner, and R. D. Methot. 2011. Estimating natural mortality within a fisheries stock assessment model: An evaluation using simulation analysis based on twelve stock assessments. Fisheries Research 109:89-94 doi:10.1016/j.fishres.2011.01.021.

Lewy, P., and M. Vinther. 2004. A stochastic age-length-structured multispecies model applied to North Sea stocks. ICES CM 2004/FF: 20.

Link, J. 2010. Ecosystem-based fisheries management: confronting tradeoffs. Cambridge University Press ISBN:1139493027.

Lorenzen, K. 1996. The relationship between body weight and natural mortality in juvenile and adult fish: a comparison of natural ecosystems and aquaculture. Journal of Fish Biology 49:627-642 doi:10.1111/j.1095-8649.1996.tb00060.x.

Miller, T. J., J. A. Hare, and L. A. Alade. 2016. A state-space approach to incorporating environmental effects on recruitment in an age-structured assessment model with an application to southern New England yellowtail flounder. Canadian Journal of Fisheries and Aquatic Sciences 73:1261-1270 doi:10.1139/cjfas-2015-0339.

Miller, T. J., and S.-Y. Hyun. 2018. Evaluating evidence for alternative natural mortality and process error assumptions using a state-space, age-structured assessment model. Canadian Journal of Fisheries and Aquatic Sciences 75:691-703 doi:10.1139/cjfas-20170035 .

Moffitt, E. A., A. E. Punt, K. Holsman, K. Y. Aydin, J. N. Ianelli, and I. Ortiz. 2016. Moving towards ecosystem-based fisheries management: Options for parameterizing multi-species biological reference points. Deep Sea Research Part II: Topical Studies in Oceanography 134:350-359 doi:https://doi.org/10.1016/j.dsr2.2015.08.002.

Nielsen, A., and C. W. Berg. 2014. Estimation of time-varying selectivity in stock assessments using state-space models. Fisheries Research 158:96-101 doi:10.1016/j.fishres.2014.01.014. 
NOAA. 2016. Ecosystem-Based Fisheries Management Policy of the National Marine Fisheries Service, National Oceanic and Atmospheric Administration. Page 8 in Department of Commerce, editor. National Marine Fisheries Service Policy Directive 01-120.

Northeast Fisheries Science Center. 2015. Operational Assessment of 20 Northeast Groundfish Stocks, Updated Through 2014. Page 251 in US Department of Commerce, editor., Northeast Fisheries Science Center Reference Documents 15-24.

Owen-Smith, N., and M. G. L. Mills. 2008. Shifting prey selection generates constrating herbivore dynamics within a large-mammal predator-prey web. Ecology 89:1120-1133 doi:10.1890/07-0970.1.

Peterson, I., and J. S. Wroblewski. 1984. Mortality Rate of Fishes in the Pelagic Ecosystem. Canadian Journal of Fisheries and Aquatic Sciences 41:1117-1120 doi:10.1139/f84-131.

Plagányi, É. E. 2007. Models for an ecosystem approach to fisheries. Page 108 in Food and Agriculture Organization of the United Nations, editor. FAO Fisheries Technical Paper 477, Rome.

Plagányi, É. E., A. E. Punt, R. Hillary, E. B. Morello, O. Thébaud, T. Hutton, R. D. Pillans, J. T. Thorson, E. A. Fulton, A. D. M. Smith, F. Smith, P. Bayliss, M. Haywood, V. Lyne, and P. C. Rothlisberg. 2014. Multispecies fisheries management and conservation: tactical applications using models of intermediate complexity. Fish and Fisheries 15:1-22 doi:10.1111/j.1467-2979.2012.00488.x.

Schwarz, G. 1978. Estimating the dimension of a model. The annals of statistics 6:461-464.

Skern-Mauritzen, M., G. Ottersen, N. O. Handegard, G. Huse, G. E. Dingsør, N. C. Stenseth, and O. S. Kjesbu. 2015. Ecosystem processes are rarely included in tactical fisheries management. Fish and Fisheries 17:165-175 doi:10.1111/faf.12111.

Smith, B. E., and J. S. Link. 2010. The trophic dynamics of 50 finfish and 2 squid species on the northeast US continental shelf. Page 646 in US Department of Commerce, editor. NOAA Technical Memorandum NMFS-NE-216.

Thompson, W. R. 1936. On Confidence Ranges for the Median and Other Expectation Distributions for Populations of Unknown Distribution Form. The Annals of Mathematical Statistics 7:122-128 doi:10.1214/aoms/1177732502.

This article is protected by copyright. All rights reserved 
Trijoulet, V., G. Fay, and T. J. Miller. 2019. Data from: Performance of a state-space multispecies model: what are the consequences of ignoring predation and process errors in stock assessments? Zenodo https://doi.org/10.5281/zenodo.3407512

Trijoulet, V., G. Fay, K. Curti, B. Smith, and T. J. Miller. 2019. Performance of multispecies assessment models: insights on the influence of diet data. ICES Journal of Marine Science doi:10.1093/icesjms/fsz053.

Tsehaye, I., M. L. Jones, J. R. Bence, T. O. Brenden, C. P. Madenjian, and D. M. Warner. 2014. A multispecies statistical age-structured model to assess predator-prey balance: application to an intensively managed Lake Michigan pelagic fish community. Canadian Journal of Fisheries and Aquatic Sciences 71:627-644 doi:10.1139/cjfas-2013-0313.

Tsou, T.-S., and J. S. Collie. 2001. Estimating predation mortality in the Georges Bank fish community. Canadian Journal of Fisheries and Aquatic Sciences 58:908-922 doi:10.1139/f01-044.

Ursin, E. 1967. A Mathematical Model of Some Aspects of Fish Growth, Respiration, and Mortality. Journal of the Fisheries Research Board of Canada 24:2355-2453 doi:10.1139/f67-190.

Weijerman, M., E. A. Fulton, and R. E. Brainard. 2016. Management Strategy Evaluation Applied to Coral Reef Ecosystems in Support of Ecosystem-Based Management. PloS one 11:e0152577 doi:10.1371/journal.pone.0152577.

This article is protected by copyright. All rights reserved 
Table 1: Equations of the operating multispecies model.

\begin{tabular}{|c|c|c|c|}
\hline Number & Name & Equation & Comments \\
\hline \multicolumn{4}{|c|}{ Structural model } \\
\hline $\mathrm{T} 1.1$ & $\begin{array}{l}\text { Predicted } \\
\text { number at } \\
\text { age } a \text { and } \\
\text { year } t \text { of fish } \\
\text { species } i\end{array}$ & $\begin{array}{c}\hat{N}_{t+1, a+1, i}=N_{t, a, i} e^{-Z_{t, a, i}} \\
\hat{N}_{t+1, A_{i} i}=N_{t, A_{i}, i} e^{-Z_{t, A_{i} i}}+N_{t+1, A_{i} i} e^{-Z_{t+1, A_{i} i}}\end{array}$ & $\begin{array}{l}A \text { is the age plus } \\
\text { group. Number at } \\
\text { age in the } 1^{\text {st }} \text { year } \\
\hat{N}_{t=1, a, i} \text { are } \\
\text { estimated } \\
\text { parameters }\end{array}$ \\
\hline $\mathrm{T} 1.2$ & $\begin{array}{l}\text { Total } \\
\text { mortality }\end{array}$ & $Z_{t, a i}=F_{t, a, i}+M_{i}+P_{t, a, i}$ & $\begin{array}{l}\text { The natural } \\
\text { mortality }(M) \text { is fixed } \\
\text { at } 0.2 \text { and } 0.35 \text { for } \\
\text { cod and herring } \\
\text { respectively }\end{array}$ \\
\hline $\mathrm{T} 1.3$ & $\begin{array}{l}\text { Fishing } \\
\text { mortality }\end{array}$ & $F_{t, a, i}=f_{t} s_{a, i}^{F}$ & $\begin{array}{l}f \text { is the freely } \\
\text { estimated fully } \\
\text { selected fishing } \\
\text { mortality }\end{array}$ \\
\hline T1.4 & $\begin{array}{l}\text { Fishing } \\
\text { selectivity }\end{array}$ & $s_{a, i}^{F}=\frac{1}{1+e^{\left(-\left(\frac{a_{i}-A 50_{i}^{F}}{\gamma_{i}^{F}}\right)\right)}}$ & $\begin{array}{l}\text { Logistic form where } \\
\gamma^{F} \text { and } A 50^{F} \text { are } \\
\text { estimated } \\
\text { parameters on a logit } \\
\text { scale }\end{array}$ \\
\hline T1.5 & $\begin{array}{l}\text { Predation } \\
\text { mortality }\end{array}$ & $P_{t, a, i}=\sum_{b=1}^{B}\left(\right.$ cons_rate $\left._{b} N_{t, b} \frac{\vartheta_{t, a, i, b}}{\sum_{i=1}^{I} \sum_{a=1}^{A_{i}} \phi_{t, a, i, b}+\phi_{\text {other }_{t, b}}}\right)$ & $\begin{array}{l}\text { cons_rate is the per- } \\
\text { capita consumption } \\
\text { rate of cod of age } b \\
\text { and maximum age } B \\
\text { and is given in } \\
\text { Trijoulet et al. } \\
(2019)\end{array}$ \\
\hline T1.6 & $\begin{array}{l}\text { Biomass of } \\
\text { modelled } \\
\text { prey available }\end{array}$ & $\phi_{t, a, i, b}=\vartheta_{t, a, i, b} N_{t, a, i} w_{t, a, i}$ & \\
\hline
\end{tabular}

This article is protected by copyright. All rights reserved 


\begin{tabular}{|c|c|c|c|}
\hline & to cod & & \\
\hline T1.7 & $\begin{array}{l}\text { Prey } \\
\text { suitability }\end{array}$ & $\vartheta_{t, a, i, b}=\rho_{i} g_{t, a, i, b}$ & $\begin{array}{l}\rho \text { is the estimated } \\
\text { prey general } \\
\text { vulnerability }\end{array}$ \\
\hline T1.8 & $\begin{array}{l}\text { Cod size } \\
\text { preference }\end{array}$ & $g_{t, a, i, b} \sim \operatorname{Gamma}\left(\log \left(\frac{w_{t, b}}{w_{t, a, i}}\right), 0.552,9.308\right)$ & Gamma distribution \\
\hline T1.9 & $\begin{array}{l}\text { Biomass of } \\
\text { other food } \\
\text { available }\end{array}$ & $\phi_{\text {other }}=\rho_{\text {other }} B_{\text {other }}$ & $\begin{array}{l}B_{\text {other }}=15000 \mathrm{t} \text { and } \\
\rho_{\text {other }}=1-\sum_{i=1}^{I} \rho_{i, j}\end{array}$ \\
\hline T1.10 & $\begin{array}{l}\text { Predicted } \\
\text { survey } \\
\text { abundance } \\
\text { index }\end{array}$ & $\hat{I}_{t, a, i}=q_{i} S_{a, i}^{\text {surv }} N_{t, a, i} e^{-\psi_{t} Z_{t, a, i}}$ & $\begin{array}{l}\psi \text { is the fraction of } \\
\text { the year elapsed } \\
\text { when the survey } \\
\text { takes place }\end{array}$ \\
\hline $\mathrm{T} 1.11$ & $\begin{array}{l}\text { Survey } \\
\text { catchability }\end{array}$ & $q_{i}=\frac{1}{1+e^{-\log _{\text {it }} q_{i}}}$ & Freely estimated \\
\hline T1.12 & $\begin{array}{l}\text { Survey } \\
\text { selectivity }\end{array}$ & $s_{a, i}^{\text {surv }}=\frac{1}{1+e^{\left(-\left(\frac{a_{i}-A 50_{i}^{\text {surv }}}{\gamma_{i}^{\text {surv }}}\right)\right)}}$ & $\begin{array}{l}\text { Logistic form where } \\
\gamma^{\text {surv }} \text { and } A 50^{\text {surv }} \text { are } \\
\text { estimated } \\
\text { parameters on a logit } \\
\text { scale }\end{array}$ \\
\hline T1.13 & $\begin{array}{l}\text { Predicted } \\
\text { fishing catch }\end{array}$ & $\hat{C}_{t, a, i}=\frac{F_{t, a, i}}{Z_{t, a, i}} N_{t, a, i}\left(1-e^{-Z_{t, a, i}}\right)$ & Baranov equation \\
\hline T1.14 & $\begin{array}{l}\text { Spawning } \\
\text { stock } \\
\text { biomass }\end{array}$ & $S S B_{t, i}=\sum_{a=1}^{A_{i}}\left(N_{t, a, i} w_{t, a, i}^{S S B} m a t_{t, a, i} e^{-\varphi_{i} Z_{t, a, i}}\right)$ & $\begin{array}{l}w^{S S B} \text { is the observed } \\
\text { weight in the SSB, } \\
\text { mat is the } \\
\text { proportion of mature } \\
\text { fish at age and } \varphi \text { is } \\
\text { the fraction of the } \\
\text { year elapsed when } \\
\text { the spawning takes } \\
\text { place }\end{array}$ \\
\hline \multicolumn{4}{|c|}{ Likelihood components } \\
\hline
\end{tabular}

This article is protected by copyright. All rights reserved 


\begin{tabular}{|c|c|c|c|}
\hline T1.15 & $\begin{array}{l}\text { Fit to observed } \\
\text { aggregated } \\
\text { catch }\end{array}$ & $\log \left(C_{t, i}\right) \mid N_{t, a, i} \sim \mathcal{N}\left(\log \left(\sum_{a=1}^{A_{i}} \hat{C}_{t, a, i} w_{t, a, i}\right), \sigma_{C_{t, i}}^{2}\right)$ & $\begin{array}{l}\text { The observation } \\
\text { variance }\left(\sigma_{C}^{2}\right) \text { is given } \\
\text { as input }\end{array}$ \\
\hline T1.16 & $\begin{array}{l}\text { Fit to observed } \\
\text { aggregate } \\
\text { survey indices }\end{array}$ & $\log \left(I_{t, i, k}\right) \mid N_{t, a, i} \sim \mathcal{N}\left(\log \left(\sum_{a=1}^{A_{i}} \hat{I}_{t, a, i, k}\right), \sigma_{I_{t, i, k}}^{2}\right)$ & $\begin{array}{l}\text { The observation } \\
\text { variance }\left(\sigma_{I}^{2}\right) \text { is given } \\
\text { as input }\end{array}$ \\
\hline $\mathrm{T} 1.17$ & $\begin{array}{l}\text { Fit to age } \\
\text { composition in } \\
\text { observed catch }\end{array}$ & $\log \left(\frac{C_{t, a, i}}{\sum_{a=1}^{A_{i}} C_{t, a, i}}\right) \mid N_{t, a, i} \sim$ Multinom $\left(\log \left(\frac{\hat{C}_{t, a, i}}{\sum_{a=1}^{A_{i}} \hat{C}_{t, a, i}}\right)\right)$ & $\begin{array}{l}\text { Multinomial } \\
\text { distribution }\end{array}$ \\
\hline T1.18 & $\begin{array}{l}\text { Fit to age } \\
\text { composition in } \\
\text { observed } \\
\text { survey indices }\end{array}$ & $\log \left(\frac{I_{t, a, i, k}}{\sum_{a=1}^{A_{i}} I_{t, a, i, k}}\right) \mid N_{t, a, i} \sim$ Multinom $\left(\log \left(\frac{\hat{I}_{t, a, i, k}}{\sum_{a=1}^{A_{i}} \hat{I}_{t, a, i, k}}\right)\right)$ & $\begin{array}{l}\text { Multinomial } \\
\text { distribution }\end{array}$ \\
\hline T1.19 & $\begin{array}{l}\text { Fit to prey } \\
\text { proportions in } \\
\text { the diet of the } \\
\text { predator }\end{array}$ & $\frac{\sum_{a=1}^{A_{n}} \phi_{t, a, n, b, j}}{\text { pother }_{t, b, j}+\sum_{i=1}^{I} \sum_{a=1}^{A_{i}} \phi_{t, a, i, b, j}} \sim$ Dirichlet $\left(\frac{\text { stom }_{t, n, b, j}}{\sum_{n=1}^{I+1} \text { stom }_{t, n, b, j}}, \kappa_{j}\right)$ & $\begin{array}{l}n \text { is the index for prey } \\
\text { including other food. } \\
\kappa_{j} \text { is an estimated } \\
\text { parameter }\end{array}$ \\
\hline \multicolumn{4}{|c|}{ Process errors } \\
\hline $\mathrm{T} 1.20$ & $\begin{array}{l}\text { Random } \\
\text { recruitment }\end{array}$ & $\log \left(N_{t+1, a=1, i}\right) \sim \mathcal{N}\left(\log \left(\bar{R}_{i}\right), \sigma_{R_{i}}^{2}\right)$ & $\begin{array}{l}\bar{R} \text { is the mean } \\
\text { recruitment and } \sigma_{R}^{2} \text { the } \\
\text { variance around the } \\
\text { mean }\end{array}$ \\
\hline $\mathrm{T} 1.21$ & $\begin{array}{l}\text { Random } \\
\text { abundance at } \\
\text { age }\end{array}$ & $\log \left(N_{t+1, a+1, i}\right) \mid N_{t, a, i} \sim \mathcal{N}\left(\log \left(N_{t, a, i}\right), \sigma_{N_{i}}^{2}\right)$ & $\begin{array}{l}\sigma_{N}^{2} \text { is the process error } \\
\text { variance }\end{array}$ \\
\hline
\end{tabular}


Table 2: Convergence rate in percent for each estimation models.

\begin{tabular}{|l|l|l|l|}
\hline EM1 & EM2 & EM3 & EM4 \\
\hline 77.5 & 93.1 & 30.7 & 29.3 \\
\hline
\end{tabular}

This article is protected by copyright. All rights reserved 
Figure 1: Median relative differences and 95\% confidence interval for some estimated parameters. Each plot correspond to a specific estimation model (EM). Note the change in the $y$ axis.

Figure 2: Median relative differences and 95\% confidence interval for estimated numbers of fish at age in the first year of simulation. Each plot correspond to a specific estimation model (EM). Note the change in the y-axis.

Figure 3: Median relative differences and 95\% confidence interval for the estimated process error variances in abundance at age $\left(\sigma_{N}\right)$ and recruitment $\left(\sigma_{R}\right)$. Note the change in the y-axis.

Figure 4: Median relative differences in spawning stock biomass (SSB) and recruitment (R). Annual values of SSB and recruitment are aggregated within each boxplot. Note the change in the y-axis.

Figure 5: Median relative differences in estimated fishing mortality $(F)$, predation mortality $(P)$ and residual natural mortality $(M)$. Year and age component are aggregated within the boxplot. For EM1 and EM2, $M$ is given as median relative difference with $95 \%$ confidence interval because only one value is estimated per EM (M constant across age and time). For EM3 and EM4, predation is not explicitly estimated so the value for $M$ is compared to $M+P$. Note the change in the y-axis.

Figure 6: Distributions of differences between negative log-likelihood (NLL) values for EM1 with NLLs for EM2, EM3 and EM4, for all converged iterations and for each observation component. Positive values represent an improvement in fit and inversely. The grey dashed line shows the distribution median.

Figure 7: Median relative difference and 95\% confidence interval in the last 10 years of aggregated survey indices for the simulations where the last 5 years of observed survey indices were not included in the model fitting procedure. Note the change in the y-axis.

This article is protected by copyright. All rights reserved 
Figure 8: Median relative difference and 95\% confidence interval in the last 10 years of spawning stock biomass for the simulations where the last 5 years of observed survey indices were not included in the model fitting procedure. Note the change in the y-axis.

Figure 9: Median relative difference and 95\% confidence interval for the absolute unfished biomass $\left(B_{0}\right)$ and relative $\left(\frac{S B_{y}=42}{B_{0}}\right)$ reference point estimates when process errors were assumed in the forecasts for OM, EM1, EM3 and EM4.

Figure 10: Ratio of equilibrium SSB against $B_{0}$ for both species as a function of change in fishing mortality on both stocks for the OM.

This article is protected by copyright. All rights reserved 


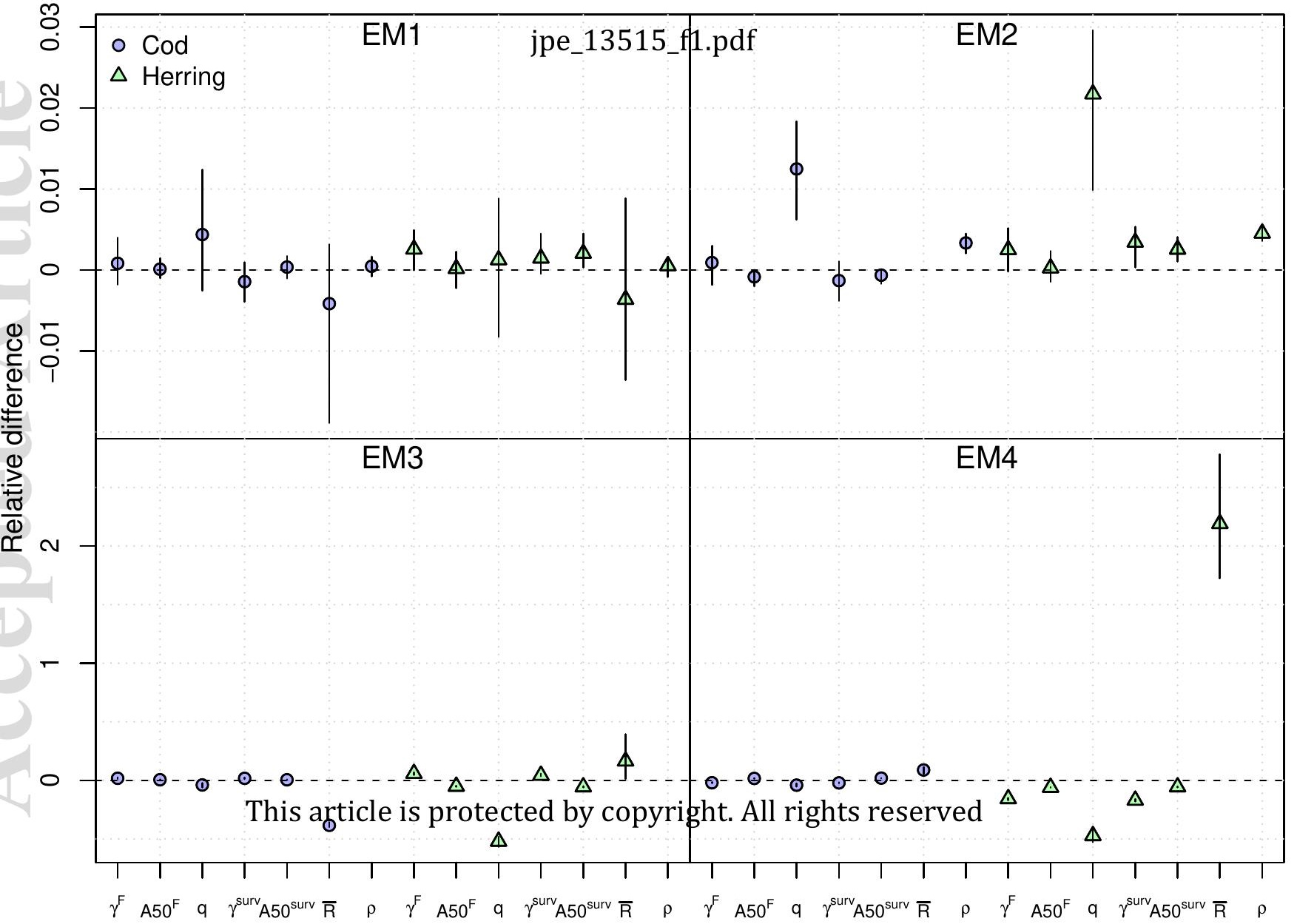


Relative difference

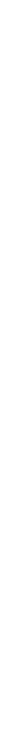




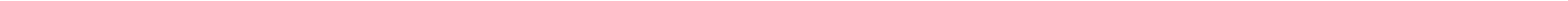




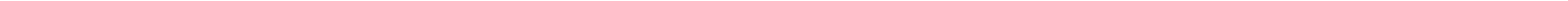




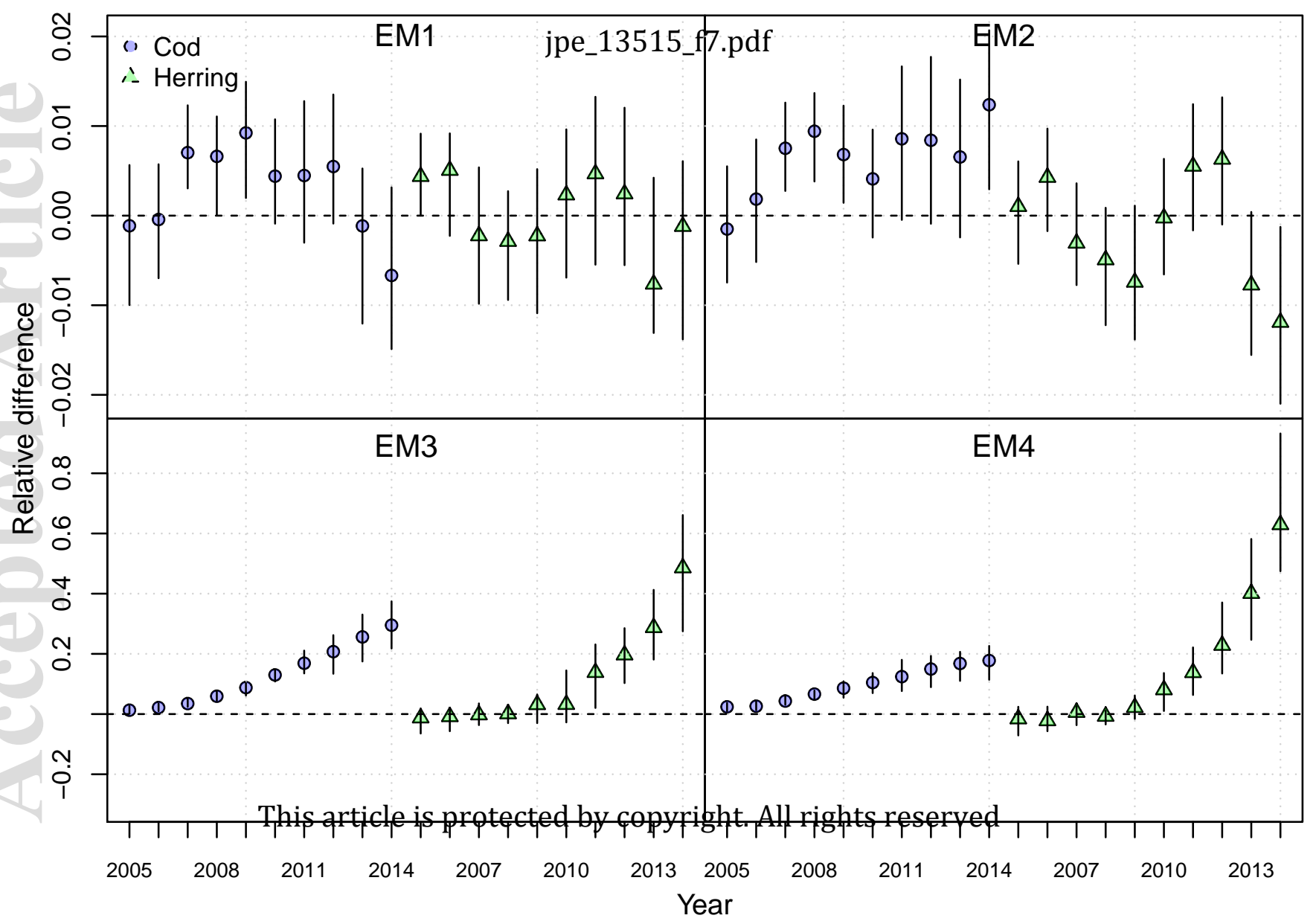




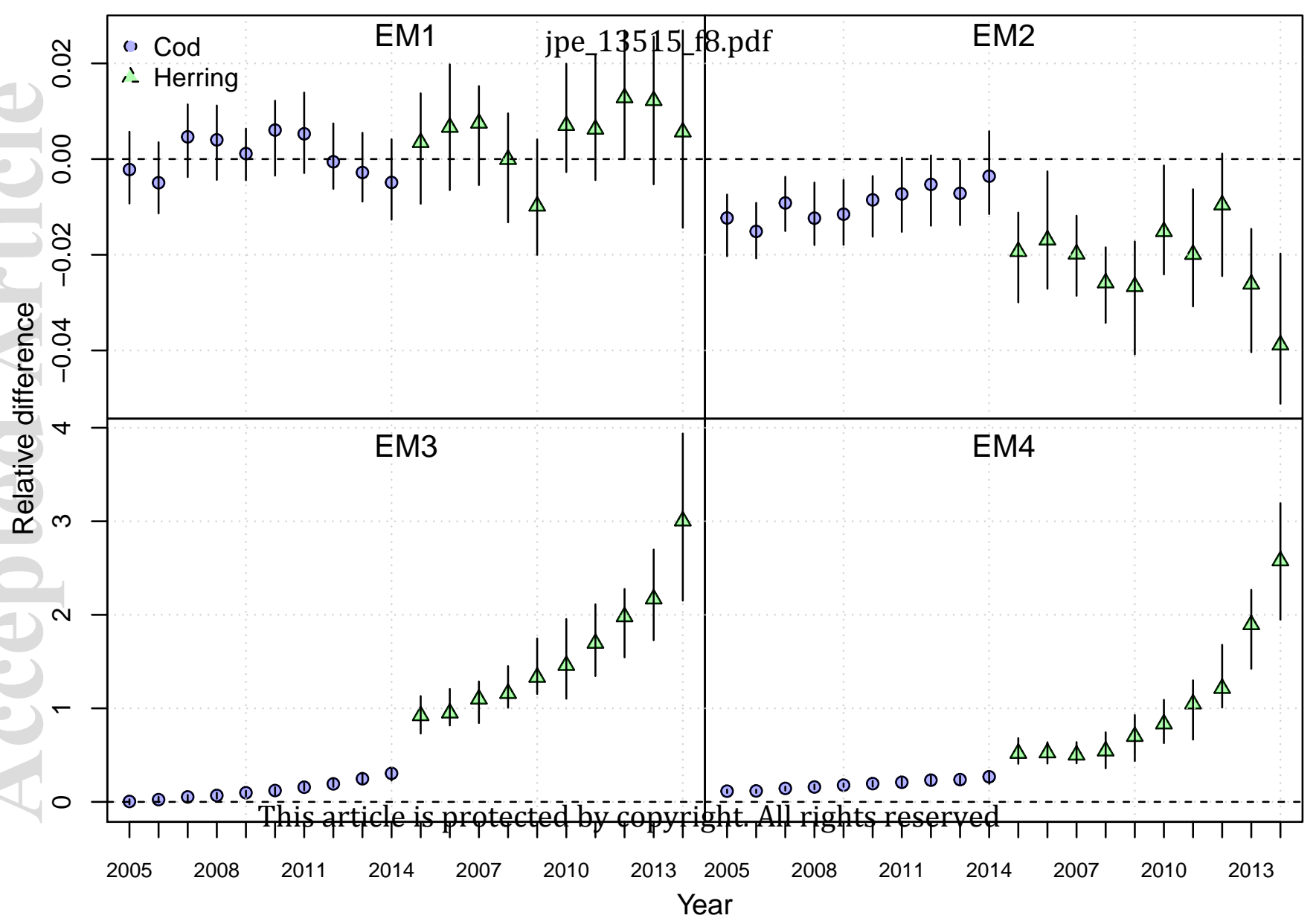




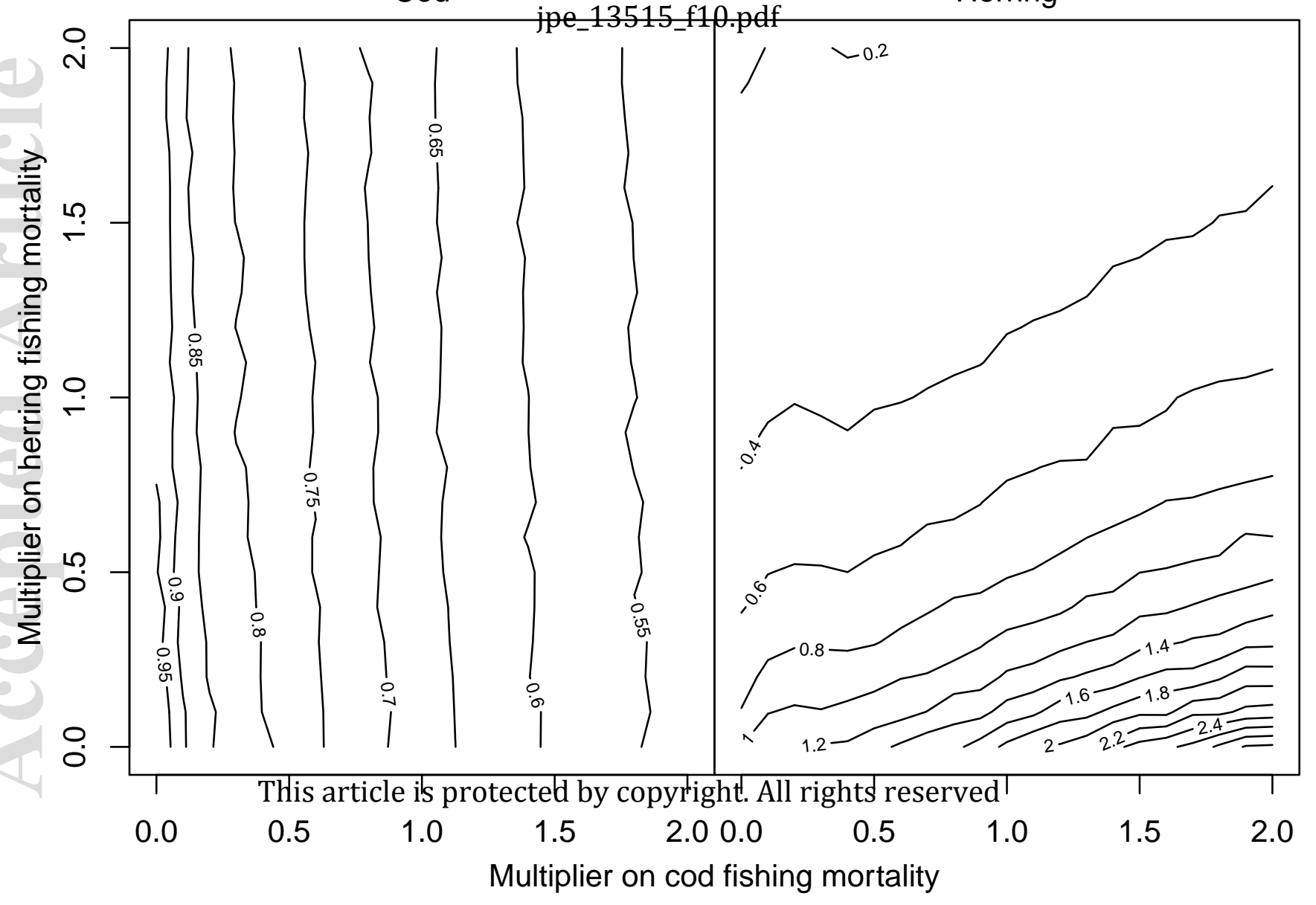

